\title{
Perbedaan Perilaku Anak Prasekolah Berdasarkan Pola Pengasuhan
}

Tri Sondang Kartikawati Situmorang, Nurnaningsih, Retno Sutomo

Bagian Ilmu Kesehatan Anak Fakultas Kedokteran Universitas Gadjah Mada/RSUP Dr. Sardjito, Yogyakarta

Latar belakang. Perkembangan anak, termasuk perkembangan perilaku dan psikologis, merupakan hal penting yang harus menjadi perhatian bagi orang tua; karena akan memengaruhi masa depan anak. Dasar-dasar pembentukan kepribadian dan perilaku ditentukan oleh apa yang dialami serta dihayati dalam 5-6 tahun pertama. Pola asuh merupakan proses di dalam keluarga yang merupakan interaksi orang tua dan anak. Pola asuh orang tua diyakini memengaruhi perilaku anak.

Tujuan. Menilai perbedaan proporsi kejadian gangguan perilaku anak usia prasekolah berdasar perbedaan pola pengasuhan orang tua. Metode. Penelitian observasional analitis dengan desain cross sectional di Yogyakarta antara Maret-April 2014. Pola asuh orang tua dan perilaku anak masing-masing dinilai dengan the parenting scale dan strengths and difficulties questionnaire (SDQ). Kriteria inklusi ialah anak usia prasekolah usia 3-6 tahun dan orang tua setuju ikut penelitian. Subjek dieksklusi bila pengisian perangkat penelitian dinilai tidak lengkap. Perbedaan proporsi gangguan perilaku antara pola asuh demokratis dan non-demokratis dianalisis dengan uji chi square. Hasil. Hasil penelitian menunjukkan kedua pola asuh berhubungan dengan kejadian gejala emosional ( $\mathrm{p}=0,00)$, kejadian menimbulkan masalah $(\mathrm{p}=0,01)$, kejadian hiperaktif $(\mathrm{p}=0,00)$, masalah anak dengan sebaya $(\mathrm{p}=0,00)$ dan antara pola asuh orang tua dengan total kejadian gangguan perilaku anak $(\mathrm{p}=0,00)$.

Kesimpulan. Pola pengasuhan yang berbeda akan menghasilkan perilaku yang berbeda pula. Sari Pediatri 2016;18(4):314-9

Kata kunci: pola asuh, perilaku anak, SDQ

\section{Differences in Child Behaviors among Preschooler by Parenting Styles}

Tri Sondang Kartikawati Situmorang, Nurnaningsih, Retno Sutomo

Background. It is important for parents to concern to child development, including behavioral and psychological development, since it determines the child's future. Foundation for child behavior and personality is mainly based on internalization of their experiences within the first 5-6 years. Parenting involves interaction of parents and children whitin family unit. Parenting style has been suggested to be associated with a child behavior.

Objective. This study was aimed to analyze the difference in prevalence of preschool child behaviors by parenting style

Method. We conduct analytical observational study with cross-sectional design in Yogyakarta between March-April 2014. Parenting styles and child behaviors were assessed by the parenting scale and strength and difficulty questionnaire, respectively. Inclusion criteria are preschoolers aged 3-6 years and their parents agreed to join the study. Subjects with incomplete fulfillment of the questionnaires were excluded from the study. The difference in child behavior between democratic and non-democratic parenting style is analyzed by chi square test.

Results. The results showed both parenting associated with the incidence of emotional symptoms $(p=0,00)$, the incidence cause problems $(\mathrm{p}=0,01)$, the incidence of hyperactivity $(\mathrm{p}=0,00)$, children with peer problems $(\mathrm{p}=0,00)$ and between parenting parents with a total incidence of child behavior disorders $(\mathrm{p}=0,00)$.

Conclusion. Different parenting patterns will produce different behavior. Sari Pediatri 2016;18(4):314-9

Keywords: parenting, child behavior, SDQ

Alamat korespondensi: Dr.TS. Kartikawati Situmorang, Bagian Ilmu Kesehatan Anak, Fakultas Kedokteran Universitas Gadjah Mada/RSUP Dr. Sardjito Yogyakarta, Jalan Kesehatan No. 1 Sekip Yogyakarta 55284. Email: ikasondang@gmail.com 
Tri Sondang Kartikawati Situmorang dkk: Perbedaan perilaku anak prasekolah berdasarkan pola pengasuhan

$\mathrm{P}$ erkembangan anak merupakan hal penting yang harus menjadi perhatian bagi orang tua karena akan memengaruhi masa depan anak. ${ }^{1}$ Dasar-dasar pembentukan kepribadian dan perilaku ditentukan oleh apa yang dialami serta dihayati oleh anak dalam 5-6 tahun pertama. ${ }^{2}$ Pengembangan potensi jika tertunda atau terhambat dapat menimbulkan masalah. ${ }^{1}$ Sebagian besar perilaku manusia merupakan perilaku yang dibentuk atau perilaku yang dipelajari. Pembentukan perilaku terjadi karena kebiasaan, pengertian, dan menggunakan model sebagai contoh. ${ }^{2}$

Pendidikan pertama diperoleh anak di awal kehidupannya dari keluarga, khususnya orang tua. Pendidikan dapat diberikan dalam bentuk pola asuh, sikap atau tingkah laku yang dicontohkan oleh orang tua terhadap anak dalam kehidupan sehari-hari. Pola asuh merupakan proses di dalam keluarga, suatu interaksi orang tua dan anak adalah cara terbaik untuk mendidik anak. Pola asuh diterapkan sejak anak lahir dan disesuaikan dengan usia serta tahap perkembangan.

Terdapat empat macam bentuk pola asuh yang diterapkan oleh orang tua yaitu, pola asuh otoriter, demokrasi, penelantaran dan permisif. ${ }^{1}$ Pola asuh otoriter adalah pola asuh yang menuntut agar anak patuh dan tunduk terhadap semua perintah dan aturan yang dibuat oleh orang tua tanpa ada kebebasan untuk bertanya atau mengemukakan pendapat sendiri. ${ }^{3}$ Pola asuh tersebut membentuk batas dan kendali yang sangat tegas, serta memberikan hukuman fisik jika terjadi kegagalan memenuhi standar yang telah ditetapkan orang tua. Pada pola asuh otoritatif atau demokratis, orang tua mendorong anak agar mandiri namun memberikan batas dan pengendalian atas tindakan mereka. ${ }^{4}$ Pola asuh permisif atau pengasuh yang menuruti, yaitu orang tua sangat terlibat dalam kehidupan anak mereka, tetapi menetapkan sedikit batas atau kendali terhadap anak dan aturan yang ada sangatlah longgar. Pola asuh yang diterapkan oleh orang tua akan menghasilkan macam-macam bentuk perilaku moral pada anak. Penelitian sebelumnya mengemukakan bahwa anakpra sekolah yang mempunyai orangtua otoriter cenderung tidak bahagia. Mereka tampak cemas dan merasa tidak aman dengan teman sebaya, perempuan menjadi tergantung dan kurang motivasi sedangkan anak laki-laki jauh lebih mungkin untuk menjadi marah dan menantang. ${ }^{4}$

Tujuan penelitian ini adalah untuk mengetahui perbedaan proporsi kejadian gangguan perilaku anak usia prasekolah berdasarkan pola pengasuhan orang tua.

\section{Metode}

Penelitian observasional analitis dengan desain cross sectional yang dilakukan di playgroup dan taman kanakkanak di Kota Yogyakarta selama 2 bulan (Maret-April 2014). Populasi penelitian adalah adalah anak usia pra sekolah di Yogyakarta. Kriteria inklusi adalah anak usia 3-6 tahun dan orang tua setuju anaknya ikut penelitian. Subjek dieksklusi apabila pengisian perangkat penelitian tidak lengkap. Digunakan 2 perangkat bantu, yaitu the parenting scale dan strengths and difficulties questionnaire (SDQ). Besar sampel dihitung menggunakan rumus perkiraan besar sampel untuk beda proporsi dua kelompok dengan tingkat kemaknaan $\alpha 95 \%, Z 1,96$ dan power $80 \%$, didapatkan Z 0,84. Proporsi anak dengan faktor risiko untuk mendapatkan gangguan abnormal adalah 0,42 sehingga jumlah subjek 110 dengan masing-masing kelompok adalah 55 anak.

Peneliti mengadakan pertemuan dengan semua orang tua anak yang memenuhi kriteria inklusi. Didapatkan 33 pola asuh otoriter, 28 pola permisif, dan 59 pola asuh demokratis. Dilakukan random sampling sehingga didapatkan 30 anak dengan pola asuh otoriter, 25 anak pola asuh permisif, dan 55 anak pola asuh demokratis. Dilakukan wawancara dan pengisian kuesioner pada orang tua anak. Pengolahan data dengan SPSS 19.0, kemudian dilakukan analisis data menggunakan chi square. Penelitian dilakukan dengan kerja sama residen anak, pihak play group dan taman kanak-kanak serta psikolog dari Poliklinik Tumbuh Kembang RS. Dr. Sardjito Yogyakarta setelah mendapat persetujuan dari Komite Etik FK Kedokteran Universitas Gadjah Mada dan pemerintah daerah Kabupaten Kota dan Kabupaten Sleman, Provinsi Daerah Istimewa Yogyakarta.

\section{Hasil}

Data karakteristik dasar subyek penelitian tertera dalam Tabel 1, memperlihatkan anak dengan pola asuh orang tua demokratis terdiri atas laki-laki $41,8 \%$ dan perempuan $58,2 \%$. Pada pola asuh non demokratis anak laki-laki $62,7 \%$ dan anak perempuan $47,3 \%$. 
Tabel 1. Karakteristik dasar subyek penelitian

\begin{tabular}{|c|c|c|}
\hline Karakteristik & Pola asuh demokratis $(\mathrm{n}=55)$ & Pola asuh non demokratis $(\mathrm{n}=55)$ \\
\hline \multicolumn{3}{|c|}{ Jenis kelamin anak, n (\%) } \\
\hline Laki-laki & $23(41,8)$ & $29(52,7)$ \\
\hline Perempuan & $32(58,2)$ & $26(47,3)$ \\
\hline \multicolumn{3}{|l|}{ Pekerjaan bapak, n (\%) } \\
\hline Bukan PNS & $47(85,5)$ & $45(81,8)$ \\
\hline PNS & $8(44,4)$ & $10(55,6)$ \\
\hline \multicolumn{3}{|l|}{ Pekerjaan ibu, n (\%) } \\
\hline Bukan PNS & $33(51,6)$ & $31(56,4)$ \\
\hline PNS & $22(40,0)$ & $24(43,6)$ \\
\hline \multicolumn{3}{|c|}{ Lama Interaksi bapak-anak, n (\%) } \\
\hline$\leq 8 \mathrm{jam}$ & $49(89,1)$ & $50(90,9)$ \\
\hline$>8 \mathrm{jam}$ & $6(10,9)$ & $5(9,1)$ \\
\hline \multicolumn{3}{|c|}{ Lama Interaksi ibu-anak, n (\%) } \\
\hline$\leq 8 \mathrm{jam}$ & $47(85,5)$ & $42(76,4)$ \\
\hline$>8$ jam & $8(14,5)$ & $13(23,6)$ \\
\hline \multicolumn{3}{|l|}{ Pengasuh, n (\%) } \\
\hline Ada & $11(20,0)$ & $13(23,6)$ \\
\hline Tidak & $44(80,0)$ & $42(76,4)$ \\
\hline \multicolumn{3}{|l|}{ Jumlah anak, n (\%) } \\
\hline$<3$ & $50(90,9)$ & $54(98,2)$ \\
\hline$\geq 3$ & $5(9,1)$ & $1(98,2)$ \\
\hline \multicolumn{3}{|l|}{ Penghasilan, n (\%) } \\
\hline$\leq$ Rp. $1.100 .000,00$ & $11(20,0)$ & $12(21,8)$ \\
\hline$>$ Rp. $1.100 .000,00$ & $44(85,0)$ & $43(78,2)$ \\
\hline
\end{tabular}

Tabel 2. Gangguan perilaku anak usia prasekolah berdasarkan pola pengasuhan orang tua

\begin{tabular}{lccc}
\hline Jenis gangguan perilaku & Demokratis & Non demokratis & $\mathrm{p}^{*}$ \\
\hline Gejala emosional, n (\%) & $10(18,2)$ & $34(61,8)$ & 0,00 \\
Masalah perilaku, n (\%) & $11(20)$ & $24(43,6)$ & 0,01 \\
Hiperaktivitas, n (\%) & $2(3,6)$ & $31(56,4)$ & 0,00 \\
Masalah dengan sebaya, n (\%) & $7(12,7)$ & $49(89,1)$ & 0,00 \\
\hline
\end{tabular}

* chi-square test

Hasil analisis data untuk mengetahui perbedaan proporsi kejadian perilaku anak dengan perbedaan pola pengasuhan orang tua menggunakan chi-square test, tertera pada Tabel 2. Didapatkan pola asuh orang tua berhubungan dengan kejadian gejala emosional pada anak $(\mathrm{p}=0,00)$, kejadian masalah perilaku anak $(\mathrm{p}=0,01)$, kejadian hiperaktif pada anak $(\mathrm{p}=0,00)$, dan kejadian masalah dengan teman sebaya $(\mathrm{p}=0,00)$. Pada masing-masing kejadian gangguan perilaku tampak persentase lebih besar pada pola asuh otoriter dan permisif daripada pola asuh demokratis.

\section{Pembahasan}

Anak-anak pada dasarnya senang meniru karena salah satu proses pembentukan perilaku mereka diperoleh dengan cara meniru. Dengan demikian, sosok pengasuh, yang dalam kesehariannya banyak berinteraksi dengan anak, dituntut untuk bisa memberikan contoh keteladanan yang baik. Pengasuhan yang negatif akan menimbulkan tingkah laku bermasalah pada anak.

Tidak menutup kemungkinan anak diserahkan kepada pengasuh yang kemungkinan besar tidak 
mengasuh dengan seharusnya, tetapi ada kemungkinan juga pengasuh yang dipilih adalah pengasuh terbaik. ${ }^{5}$ Sebagian besar perilaku manusia merupakan perilaku yang dibentuk atau perilaku yang dipelajari. Pembentukan perilaku dengan kebiasaan, pengertian, dan menggunakan model sebagai contoh. ${ }^{2}$ Sikap, kebiasaan, dan perilaku yang dibentuk sangat menentukan peneyesuaian diri dalam kehidupan di masa dewasanya. ${ }^{6}$ Waktu berkualitas antara orang tua dan anak tidak hanya ditentukan oleh banyak atau sedikitnya waktu pengasuhan oleh orang tua untuk anak, tetapi juga ditentukan oleh tingginya intensitas komunikasi antara orang tua dan anak. ${ }^{7}$ Semakin banyak waktu yang tersedia dan berkualitas antara orang tua dan anak maka komunikasi dan intraksi anak akan terjaga dengan baik.

Perbedaan perilaku anak prasekolah berdasarkan pola asuh otoriter dan pola asuh permisif, tertera pada Gambar 1. Pada kelima kejadian gangguan perilaku didapatkan jumlah anak yang mengalami gangguan perilaku lebih banyak pada pola asuh non-demokratis. Sama seperti penelitian sebelumnya, didapatkan anak pada pola asuh otoriter dan permisif cenderung mempunyai gangguan perilaku. ${ }^{15}$

Perilaku adalah segala sesuatu yang dilakukan oleh manusia yang dapat diamati secara langsung. ${ }^{1}$ Emosi pada dasarnya adalah dorongan untuk bertindak, timbul ketika seseorang sedang dalam sebuah situasi yang dianggap penting, rencana seketika untuk mengatasi masalah yang melibatkan perubahan pada tubuh dan wajah, aktivitas pada otak, penilaian kognitif, perasaan subjektif, dan kecenderungan melakukan suatu tindakan yang dibentuk seluruhnya oleh peraturanperaturan yang terdapat di suatu kebudayaan. ${ }^{8}$ Emosi anak pra sekolah akan memengaruhi perkembangan sosial anak. ${ }^{9}$

Pola asuh permisif membuat anak bisa menjalani hidup sesuai pilihannya sendiri, tanpa intervensi dari orang tua. Orang tua cenderung membiarkan anak tanpa pendampingan, tidak pernah memberikan aturan ataupun arahan kepada anak sehingga anak tidak tahu apakah perilakunya benar atau salah. Pola asuh permisif mengondisikan anak bertumbuh menjadi seorang yang hidup seenaknya, keras kepala, tidak mau diatur atau dipimpin, dan tidak terbiasa mengontrol emosinya. Pendekatan otoriter menghasilkan anakanak yang terluka, keras dengan dirinya, dan secara emosional cenderung tidak sehat. Sebagian anak akan menjadi pribadi yang terbiasa menekan perasaan, tertutup, dan dibayangi perasaan takut gagal, keras, kasar, agresif dan penuh pemberontakan. Emosi anak pada pola asuh otoriter cenderung datar dan dingin.

Pada kenyataannya terdapat kecenderungan orang tua menghendaki agar anak mematuhi perintah orang tua dengan alasan tertentu yang belum tentu sesuai dengan kemauan anak sehingga anak cenderung memilih perilaku tertentu dalam persepsinya. Pola asuh orang tua turut serta dalam menentukan pemilihan anak. Pada pola asuh otoriter, sangat dimungkinkan anak akan patuh dengan perintah atau pilihan orang tua karena takut dihukum atau karena takut pada orang tua. Namun, kontrol dan pengawasan orang

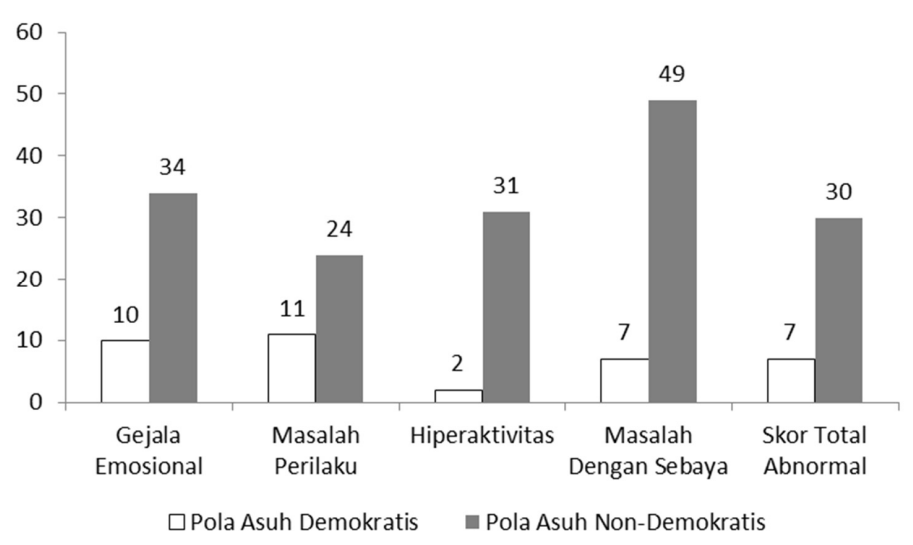

Gambar 1. Grafik perbedaan kejadian gangguan perilaku berdasarkan pola asuh otoriter dan pola asuh permisif 
tua otoriter tidak berarti tak ada gangguan masalah perilaku. Di saat ada pengawasan, anak akan patuh, tetapi berbeda di saat tidak ada pengawasan orang tua.

Lain halnya dengan pola asuh permisif, yang tidak ada pemantauan pada anak, hanya memberikan kontrol dan tuntutan yang sangat minim (selalu menuruti atau terlalu membebaskan) sehingga dapat mengakibatkan kompetensi sosial yang tidak adekuat karena umumnya anak kurang mampu untuk melakukan kontrol diri dan menggunakan kebebasannya tanpa rasa tanggung jawab serta memaksakan kehendaknya.Kemampuan berperilaku sosial perlu dimiliki oleh anak sejak masih kecil. ${ }^{1}$ Hal tersebut sebagai suatu dasar atau bekal bagi perkembangan kemampuan anak untuk berinteraksi atau berteman.

Anak dengan gangguan hiperaktif tidak bisa konsentrasi, tidak memiliki fokus yang jelas, dan melakukan sesuatu tanpa tujuan. Anak sulit untuk dikendalikan, tidak bisa diam dalam waktu lama dan mudah teralihkan, seorang penuntut jika memiliki keinginan. Orang tua sering kewalahan dan tidak sanggup meladeni perilakunya sehingga dinilai sebagai anak nakal. Anak hiperaktif cenderung tidak mampu melakukan sosialisasi dengan baik. ${ }^{10}$ Kemampuan berperilaku sosial perlu dimiliki oleh anak sejak masih kecil. ${ }^{6} \mathrm{Hal}$ tersebut sebagai suatu dasar atau bekal bagi perkembangan kemampuan anak untuk berinteraksi atau berteman. Sosialisasi diperlukan oleh anak untuk memperoleh latihan dan pengalaman. Anak yang tidak mampu berperilaku sosial dapat mengakibatkan kepercayaan diri anak tidak terbentuk sehingga anak menarik diri dari lingkungan dan akan terkucil dari lingkungannya. ${ }^{6}$ Anak akan mengalami hambatan dalam perkembangan selanjutnya. Gangguan perilaku pada anak dimulai di awal kehidupan dan mencapai puncaknya pada sekitar usia empat tahun. Sebuah penelitian menunjukkan bahwa pola gangguan perilaku itu sering tidak sampai usia masuk sekolah. ${ }^{11}$

Bertentangan dengan hasil penelitian lainnya yang menunjukkan bahwa sebagian besar dari yang sikap agresif, sifat menantang, perilaku hiperaktif balita akan terus berlanjut dengan mengalami masalah saat usia sekolah. ${ }^{12,13}$ Alasan yang membuat masalah perilaku lebih sering terjadi pada masa kanak-kanak karena pada masa tersebut sedang terjadi proses pembentukan kepribadian yang kadang-kadang kurang berhasil. Pada masa tersebut anak tampak bandel, keras kepala, marah tanpa alasan, serta menghabiskan waktu untuk bermain. Hal terpenting yang kadang sulit untuk dilakukan pada masa ini adalah belajar untuk berhubungan secara emosional dengan orang tua, saudara, serta orang lain yang ikut merawat ataupun orang lain yang disekitarnya. ${ }^{7}$ Pendidikan pra sekolah menjadi sangat penting untuk pembinaan menyeluruh pada anak. Pendidikan pra sekolah meliputi taman kanak-kanak, taman bermain (playgroup) dan penitipan anak. Taman kanak-kanak merupakan jalur pendidikan, sedangkan playgroup dan penitipan anak berada di jalur luar pendidikan. ${ }^{13}$

Pada penelitian ini, didapatkan bahwa pola asuh berhubungan dengan masalah dengan sebaya. Sosialisasi diperlukan oleh anak untuk memperoleh latihan dan pengalaman. Hubungan sosial dianggap sebagai hal yang sangat penting bagi anak. Anak dengan pola asuh permisif sering mengalami gangguan emosi atau temperamen yang agresif serta sering ditolak oleh teman sebaya. Kemampuan mengatur emosi juga memengaruhi perilaku sosial anak. Anak dengan pola asuh otoriter cenderung mudah terluka secara psikis, biasanya akan takut atau malu-malu dalam menghadapi stimulus sosial yang baru.

Anak yang mampu bersosialisasi dan mengatur emosi akan memiliki perilaku sosial yang baik sehingga kompetensi aspek sosial juga tinggi. Anak yang kurang mampu bersosialisasi, tetapi mampu mengatur emosi, akan tetap mampu bermain dan berinteraksi dengan teman sebayanya, melakukan eksplorasi saat bermain. Sedangkan anak- anak yang mampu bersosialisasi, tetapi kurang dapat menggontrol emosi cenderung akan berperilaku agresif dan merusak. Anak yang tidak mampu bersosialisasi dan mengontrol emosi akan cenderung lebih pencemas dan kurang berani dalam berinteraksi dengan teman sebayanya.

Pada pola asuh demokratis memprioritaskan kepentingan anak, akan tetapi tidak ragu-ragu mengendalikan mereka. Orang tua dengan pola asuh ini bersikap rasional, selalu mendasari tindakannya pada rasio atau pemikiran-pemikiran, bersikap realistis terhadap kemampuan anak, tidak berharap yang berlebihan yang melampaui kemampuan anak. Orang tua dengan pola asuh demokratis juga memberikan kebebasan kepada anak untuk memilih dan melakukan suatu tindakan, dan pendekatannya kepada anak bersifat hangat.

Kebutuhan anak dapat terpenuhi apabila orang tua dalam memberi pengasuhan dapat mengerti, 
memahami, menerima, dan memperlakukan anak sesuai dengan tingkat perkembangan psikis anak, disamping menyediakan fasilitas bagi pertumbuhan fisiknya. Masing-masing pola asuh ini mempunyai dampak bagi perkembangan anak.

Pola asuh demokratis menjadi jalan terbaik dalam pembentukan karakter anak karena pola asuh ini menghargai dan memahami keadaan anak dengan kelebihan kekurangannya sehingga anak dapat menjadi pribadi yang matang, supel, dan bisa menyesuaikan diri dengan baik.

\section{Daftar pustaka}

1. Santrock JW. Perkembangan anak. Edisi kesebelas. Jakarta: Erlangga;2007.

2. Walgito B. Psikologi sosial : suatu pengantar. Edisi kedua. Jogjakarta: Andi; 2004.

3. Aurola K, Nurmi JE. The role of parenting style in children problem behavior. Child Development 2005;75:1144-1159.

4. Baumrind D. The influence of parenting style on adolescent competence and substance abuse. J Early Adoles 1991;1:56-95.

5. Unicef. English children at risk because mother go back to work too soon. The Telegraph 2008; 1. Diakses 20 November 2016. Didapat dari: http://www.telegraph.co.uk/ news/uknews/3701376/Unicef-English-children-at-risk-becausemothers-go-back-to-work-too-soon.html.
6. Hurlock E. Psikologi perkembangan. Jakarta : Erlangga; 1990.

7. McMunn A, Kelly Y, Cable N, Bartley M. Maternal employment and child socio-emotional behaviour in The UK: longitudinal evidence from the uk millenium cohort study. J Epidemiol Community Health 2011;66:7-19.

8. Wade C, Travis. Psikologi. Edisi Ke-9. Jakarta : Erlangga; 2007.

9. Masruroh. Perempuan karier dan pendidikan anak : idealitas pola pembelajaran play group. Semarang: RaSail Media Group; 2011.

10. Sarwono SW. Pengantar psikologi Umum. Jakarta: Rajawali Pers; 2009.h.10-35.

11. Campbell SB, Shaw DS, Gilliom M. Early externalising behaviour problems: toddlers and pre-schoolers at risk for later maladjustment. Dev Psychopathol 2000;12:467-88.

12. Champell SB. Behaviour problems in preschool children : a review of recent research. J Child Psychol Psychiatry 1995;36:115-9

13. Shaw DS, Winslow EB, Flanagan C. A prospective study of the effects of marital status and family relations on young children's adjustment among African American and Caucasian families. Child Development 1999;70:742-55.

14. Strazdins L, Shipley M, Clements M, Obrien LV, Broom $\mathrm{DH}$. Job quality and inequality: parents' jobs and children's emotional and behavioural difficulties. Social Science \& Medicine 2010;70:2052-60.

15. Ginsburg KR, Durbin DR, García-España JF, Kalicka EA, Winston FK. Associations between parenting styles and teen driving, safety-related behaviors and attitudes. Pediatrics 2009; 124:1040-51. 